\title{
Exploring the Reasons for the Fossilization of Phonological Errors: A case study of the substitu- tion of/o/for/s/by English as Second Language Learners in Sri Lanka
}

Kaushika Premarathne*

Department of Linguistics, University of Kelaniya, Dalugama, Kelaniya, Sri Lanka, Division of Interdisciplinary Studies, Institute

of Technology, University of Moratuwa, Diyagama, Sri Lanka

Corresponding Author: Kaushika Premarathne, E-mail: kaushprem@gmail.com



\section{INTRODUCTION}

"Thus accent becomes a litmus test for exclusion, an excuse to turn away, to refuse to recognize the other." (Lippi -Green, 1997)

The above statement form Lippi Green (1997) justifies the prominent role played by pronunciation and it clearly depicts that fossilized pronunciation features have become a stigmatized marker through which a person's social, professional and educational identity can be determined. Therefore, this study is designed to explore the reasons for fossilization phonological features in the code repertoire of English as Second learners in Sri Lanka and to urge Second Language facilitators in Sri Lanka on the priority that should be placed on pronunciation teaching as errors in pronunciation can adversely affect social, professional and educational identity of Sri Lankan learners.

\section{Aim}

This study is an attempt to explore the underlying reasons for the fossilization of phonological sounds which do not exist in the first language (L1).

\section{Objective}

The objective of the study is to find out the reasons for the substitution of the mid back vowel/o/in places where the production of the low back vowel/o/is required by English as Second Language learners in Sri Lanka.

\section{Research Background}

The section below is an account of place and practices of pronunciation teaching worldwide and in Sri Lanka.

During the period of the Grammar Translation method, pronunciation teaching was completely overlooked while the priority was set on speech and oral fluency. The direct method instructed facilitators to teach pronunciation through intuition and imitation. The ultimate aim of pronunciation teaching was to attain native-like accent which deterred many teachers from teaching pronunciation as attaining native-like pronunciation was an unconquerable task. During the 1950's and the 1960's, the Audio-lingual teaching method introduced a more scientific method to teach pronunciation through the International Phonetic Alphabet and charts 
that visualize the articulation of sounds. Attention was paid to avoid errors at all cost. However, this practice was later challenged by Krashen's Monitor model which prohibited both structural grading and error correction. The advent of Communicative Language Teaching (CLT) in the 1980s, the widely accepted teaching method, encouraged learning language through communication and interaction rather than through form-focused instruction. As CLT overemphasizes the importance of phonological fluency over discrete point accuracy, today facilitators worldwide tend to disregard erroneous phonological forms made by learners if what is being communicated is comprehensible.

However, different teaching methods and approaches adopted globally from time to time have moved the emphasis on pronunciation from one extreme to another. Due to this reason, pronunciation teaching has been a neglected area in Sri Lankan ESL classrooms. Even after thirteen years of learning English as a subject, the majority of undergraduates find loud reading problematic and tend to proceed "'along a grapheme to phoneme conversion mode" (Widyalankara, 2014) which proves that pronunciation teaching has been contingently carried out at schools over the past decade. The importance placed on writing and reading skills, the lack of linguistic knowledge of teachers even after some years of pre-or in-service training (Karunarathne, 1993 cited in Karunarathne, 2003, p.13), shifting to L1 'comfort zone' both by teachers and students, students' lack of confidence and the signs of reluctance are the main reasons behind poor achievement of communicative competence of ESL learners in Sri Lanka (Karunarathne,2003) thereby limiting their exposure to the English language. A fine-grained analysis of English textbook series in Sri Lanka from grade One to grade Eleven reveals that phonetic awareness is introduced initially in grade nine (at the age of fourteen), nine years after students are introduced to the English Language which gives an account of the subsidiary place offered to pronunciation teaching. During this nine-year period, students have progressed to some extent along the interlanguage continuum and therefore their interlanguage comprises fossilized pronunciation errors which deviate from the SSLE (Premarathne, 2011).

As depicted in the past studies on phonology in Sri Lanka these phonological deviations can lead to a class distinction in Sri Lankan society (Parakrama, 1995; Gunesekera, 2005) which can even have an adverse outcome at a job interview or any social gathering. For example, Senarathne (2014) states the refection of L1 sounds in L2 classifies speakers as 'non-standard' and Gunasekara (2005) classifies two main dialectical deviations in Sri Lankan English: the High Prestige Dialect known as "Standard Sri Lankan English (SSLE)", and the Lower Prestige Dialect, often referred to by the derogatory term "Not Pot English". Those who pronounce the words which require the production of low back vowel/s/such as "not and pot" using the mid back vowel/o/ are regarded as " not pot cases" in Sri Lanka as they substitute/o/for/o/. However, the overuse of/o/for/o/has finally climaxed in fossilization of/o/sound where the production of/o/is required.

\section{Research Problem}

As evidenced in past Sri Lankan studies, phonological deviations from the SSLE stigmatize learners socially, professionally and educationally. Therefore, one can be mocked, rejected or disqualified simply based on phonological errors. Despite the substitution of/o/for/s/being a frequent occurrence in the code repertoire of English as Second Language learners, research-based studies that have investigated the underlying reasons are scarce. Therefore, the study is carried out to explore the reasons for the fossilization of the mid back vowel in the code repertoire of English as Second Language learners in Sri Lanka which will facilitate L2 facilitators and researchers to recommend various strategies that can be employed to crack the fossilized phonological errors.

\section{Theoretical Framework}

The section below records the literature on the assimilation of phonetically distinct sounds by L2 learners followed by an account which elaborates the reasons for L2 learners to perceive and produce certain phonological features which are not in compliance with the codified norms.

Flege (1992) identifies that "equivalence classification" or the inability to modify the previously established L1 sound inventory at the early stage of language learning as the central issue in the area of L2 pronunciation. According to the findings of the study, Spanish subjects perceived Spanish/i/ and English/i/as belonging to a single vowel category. This confirms that adults identify L2 sounds which are adjacent to their L1 sounds as similar to their L1 sound categories due to their well-established L1 phonological system.

Rochet (1995) studied the production of the French vowel/y/by native speakers of Canadian English and Brazilian and Portuguese speakers as the native languages of these two groups constitute only the two high vowels/i/and/u/, not the French vowel/y/. It was observed that the English group articulated the French/y/as/u/or an [u]-like vowel whereas the Portuguese learners produce it as/i/or an [i] like vowel. Rochet noticed that the French vowel/y/was produced akin to/u/ by English speakers whereas it was produced similar to/i/ by the Portuguese speakers. Rochet's study exemplifies that once an L2 sound is assimilated to an L1 category, it is produced according to the established phonetic rules of the L1.

Flege, Bohn, \& Jang (1997) studied the impact of English-language exposure on adult learners' production of L2 vowels involving a group of native speakers of German, Spanish, Mandarin, and Korean. They were grouped into "experienced" or "inexperienced" subgroups on the basis of the length of residence in the U.S. The study postulates that the exposure to L2 learning is a factor that contributes to framing certain vowels more accurately. For example, the production of the vowel/I/of the experienced group was more native-like than that of the inexperienced group for each language, although the phoneme/I/is absent in Spanish, Mandarin, and Korean languages. In contrast, no such significant impact was noticed with regard to the other three vowels, $/ \mathrm{i} /, / \varepsilon /$, and/æ/. The performance of the experienced group as observed by Flege et al. (1997) was not "completely 
native-like" albeit better than the inexperienced group. The results of the study also highlight the existence of a strong link between the perception of an L2 sound and the production of an L2 sound. For instance, the German inexperienced speakers 'attempt to distinguish between English/\&//æ/was less successful than the inexperienced Spanish speakers. Flege et al. (1997) state that the German participants may have failed to discern/๕/and/æ/as belonging to two vowel

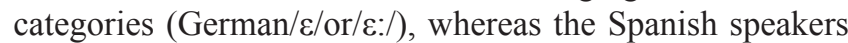
produced the two vowels as instances of two different L1 vowel categories. Therefore, the study proves the hypothesis that non-native speakers' production of English vowels directly leads to how they perceive L2 vowels.

Flege \& MacKay (2004) which was based on the perception of English vowels:/i/, I/,/eI/,/\&/,/æ/,/u/, and/or/showcases that the Italian university students who had lived in Canada for three months were unable to discriminate $/ \alpha /-/ / /, / \varepsilon /-/ æ /$ and/i/-/I/sounds as they assimilated both sounds of each category into one Italian vowel. In subsequent experiments, the perception of the English vowel contrasts by native Italian speakers who were long-time residents in Canada was examined. The participants were grouped according to the age of arrival: early and late arrivers and the percentage of first language use: high vs. low. The findings of both experiments highlight that the early learners outperformed the late learners. Similarly, low L1 use participants in the early group performed better than high L2 use participants. The study brings into focus that the establishment of the L1 specific sound system prevents learners from perceiving L2 sounds accurately. They also believe that the number of years of education in L2, L2 input from native speakers of English, and motivation are determining factors for the accurate perception of English vowels by early learners.

Cooper (2006) studied the impact of explicit teaching on pronunciation improvement. It was found that the treatment group's error rate mean score decreased from $19.9 \%$ on the first specific test to $5.5 \%$ on the second test and the control group showed no improvement as their mean error rate remained almost the same with a slight increase from $14.1 \%$ to $15.2 \%$. The findings of this study draw our attention to the significance of explicit instruction on specific forms to increase learner awareness. In a similar vein of research, Thomson (2011) utilized visuals to help learners perceive and acquire ten novel vowels. Prior to the experiment, Thomson got learners to listen and perceive the new sounds. Results confirm that perception led to production which suggests that phonological aspects should be perceived first in order to be produced.

\section{Sri Lankan Literature}

The section below draws our attention to the causes that hinder pronunciation intelligibility of Sri Lankan ESL learners as depicted in studies on phonology, undertaken to date in Sri Lanka. In the process of becoming bilingual speakers the Sinhala community 'nativizes' British pronunciation patterns by reframing the sounds of the Standard British English, substituting them for more familiar and comfortable sounds taken from the L1(Sinhala language). This situation where two languages contact commonly in social discourse has given birth to 'nativization' of certain phonological features which demonstrate more affinity to Sinhala phonology culminating in forming deviated forms from the SSLE which is discussed in the studies mentioned below.

Gunasekara (2005) on "'The Post-Colonial Identity of Sri Lankan English" records that the High Prestige Dialect of Sri Lankan English is spoken by the Sri Lankan elite who has acquired the English language from birth and use English in their educational, social and professional spheres. On the other hand, she mentions that the Lower Prestige Dialect (LPD) which is referred by the term "Not pot English" is used by the majority of Sri Lankan speakers who have no access or very limited access to English from birth and rarely use English to achieve their educational, professional or social goals daily. Gunasekera (2005) states that the SSLE encompasses two o sounds: the low back vowel/o/and the mid back vowel/o/. The lack of the low back vowel in Sinhala and the parity between the two vowels have prevented L2 learners forming the new vowel category/ $/$. As a result, Sri Lankan L2 learners tend to substitute/o/for/o/.

According to Senarathne (2014), nativization has led to the origin of deviated forms from the codified norms based on Sinhala phonological influence. Further, she elaborates the point that the "Sinhala vowel system does not contain the low back vowel/o/and therefore, most native speakers use the mid back vowel/o/to pronounce English words containing the low back vowel/o/.

Widyalankara (2014) on "Bilingual Pronunciation and First Language Dominance”, examined the correlation between L1dominance and the rate of occurrence of selected deviations from the SSLE pronunciation and states that "the bias towards L1 during language selection in functional domains and the lack of willingness to communicate in L2 result in L1 dominance in bilinguals (p.100).

Wijetunga (2008) maps out the tension between the High Prestige Dialect (HPD) and the Low Prestige Dialect (LPD) in Sri Lanka. As she mentions, this vowel contrast has become one of the key elements that differentiate the HPD from the LPD or "Not pot English". The results of the study revealed that the accuracy of the production of the low back vowel/o/is less than $25 \%$ in all the instances as participants substituted the low back vowel/o/for the mid back vowel/o/. However, as a limitation of her study, she opines that the participants were not provided with explicit instruction which may be the cause of their failure to perceive the differences between the English mid back vowel/o/\& the low back vowel/o/which is incongruent with Senarathne (2014) which highlights that the production of/o/in lone lexical items in dominant Sinhala utterances is the result of the lack of phonological awareness of English of the speaker (p.14).

Sinhala being a multiglossic language, the presence of assimilated loan words from English is high in Colloquial Sinhala. As evidenced by Widyalankara (2014) "Most of these borrowings violate not only the SBE but also the SSLE phonological grammar rules as loan pronunciation can get transferred to L2 speech discourse in weak bilinguals. According to her, "the transference of these loanword phono- 
logical contours of Sinhala to L2 pronunciation demarcates the users of Other Varieties of Sri Lankan English from the SSLE speech population (p.5)". Table one below records the graphemic representation of all core vowels and the two diphthongs of Sinhala.

As shown in Table one, there is a short of a graphemic representation for low back vowel/o/. Therefore, when loan words which require the production of/o/are written or articulated in Sinhala, the graphemic representation ' 9 ' is used in Sinhala print media or by bilingual speakers. For example, the word "office/ofIs/" is written or pronounced in Sinhala as "@கิ sentation for/o/in Sinhala. Therefore, the constant use of assimilated English loan words according to the phonological rules of the $\mathrm{L} 1$ in the long run, has fossilized the production of the low back vowel/s/akin to the mid back vow$\mathrm{el} / \mathrm{o} /$.

As recorded in the literature, nativization, the lack of awareness, the lack of exposure, motivation, age of learning and the use of assimilated loanwords in the L1 are the key determinants that hamper pronunciation intelligibility of ESL learners.

\section{Theoretical Formwork}

Based on the cognitive theory, the Interactional model advanced by Long (1996) proposes that selective attention (noticing) is facilitative for language acquisition as learners notice the gap between their interlanguage and the target language. This was also backed by Schmidt's idea of Noticing (2001) which attributes "noticing the gap and the subsequent restructuring triggered by feedback as requisites of L2 learning". According to (Swain, 1995, p.131), in order to master a language, "production of output in response to input is indispensable". When learners receive feedback on their attempts to communicate, they reformulate their initial utterances which promote language development as "'the modified output is the representation of the leading edge of a learner's interlanguage". Swain (1985), also, suggested that output practice can facilitate acquisition as it targets four cognitive processes: 'noticing, hypothesis testing, syntactic processing, and metalinguistic reflection".

\section{METHODOLOGY}

A sample of 25 high proficiency students who have studied in English medium and who are learning English as a subject at the Institute of Technology, University of Moratuwa in Sri Lanka was selected. A pilot test was conducted to find out the most common phonemic deviation from the SSLE among the participants. A questionnaire which was designed to gather data on learners 'exposure to the English Language and their experiences related to pronunciation learning at school was administered.

\section{DATA ANALYSIS AND RESULTS}

The section below presents and analyze the data gathered from the questionnaire that was administered investigate the exposure and the experiences pertaining to pronunciation learning of the participants.

Question 1: What percentage do you listen to the English language daily compared to your mother tongue?

Question 2: What percentage do you use the English language to communicate daily compared to your mother tongue?

As summarized in Table 2 and 3, all the informants have agreed that there are ample opportunities to listen to the English language as they have eight hours of lectures delivered in English medium on weekdays and as they often watch English TV series, English movies and listen to English songs. Nevertheless, all of them have stated that they communicate in English less than $10 \%$ daily in com-parison to their mother tongue. For instance, English is only used to participate in speech activities in the ESL classroom, ask or answer questions at a lecture or communicate with a non-Sinhalese batchmate. It can thus be stated the lack of opportunities to communicate in English may have contrib-uted to the unintelligible vowel production contrary to ample listening opportunities.

Question 3: Do you pronounce the two words 'hall' 'and "hole" in the same way?

Question 4: Did you know about the existence of the two contrasting vowels,/o/and/o/in English?

As depicted in Table four and five, $100 \%$ of the respondents have stated that they were not aware of the existence of two distinct vowel sounds and they produced both sounds

Table 1. Mapping Sinhala Graphemes to phonemes: Vowels (Karunatillake, 2004, p.23)

\begin{tabular}{|c|c|c|c|c|c|c|c|c|c|c|c|c|c|}
\hline ¿६ & दे & $\partial_{2}$ & C\&z & ๑ & రో & ટ & ڤે & $\theta$ & चૈ & ๑ & ๑ి & बथे & बけ \\
\hline $\mathrm{a}$ & $\mathrm{a}:$ & æ & $æ$ : & $\mathrm{i}$ & i: & $\mathrm{u}$ & $\mathrm{u}:$ & $\mathrm{e}$ & e: & o & o: & $\mathrm{aI}$ & $\mathrm{av}$ \\
\hline
\end{tabular}

Table 2. The exposure to the English Language

\begin{tabular}{|c|c|c|c|c|c|c|c|c|c|}
\hline Less than $10 \%$ & $11 \%-20 \%$ & $21-30 \%$ & $31-40 \%$ & $41-50 \%$ & $51-60 \%$ & $61 \%-70 \%$ & $71-80 \%$ & $81-90 \%$ & $91-100 \%$ \\
\hline- & - & - & - & $32 \%$ & $68 \%$ & - & - & - & - \\
\hline
\end{tabular}

Table 3. The use of the English language for communication

\begin{tabular}{lccccccccc}
\hline Less than $10 \%$ & $\mathbf{1 1 \% - 2 0 \%}$ & $\mathbf{2 1 - 3 0 \%}$ & $\mathbf{3 1 - 4 0 \%}$ & $\mathbf{4 1 - 5 0 \%}$ & $\mathbf{5 1 - 6 0 \%}$ & $\mathbf{6 1 \%}-\mathbf{- 7 0} \%$ & $\mathbf{7 1 - 8 0 \%}$ & $\mathbf{8 1 - 9 0 \%}$ & $\mathbf{9 1 - 1 0 0 \%}$ \\
\hline $100 \%$ & - & - & - & - & - & - & - & - & - \\
\hline
\end{tabular}


Table 4. Production of the low back and the mid back vowels

\begin{tabular}{lc}
\hline Yes & $100 \%$ \\
No & $0 \%$ \\
\hline
\end{tabular}

Table 5. Learner awareness

\begin{tabular}{lc}
\hline Yes & $0 \%$ \\
No & $100 \%$ \\
\hline
\end{tabular}

Table 6: Feedback on inaccurate production

\begin{tabular}{lc}
\hline Yes & $0 \%$ \\
No & $100 \%$ \\
\hline
\end{tabular}

according to their L1 phonological system as they perceived the two distinct sounds belonging to a single vowel category. This highlights that the lack of awareness of the existence of the vowel contrast may be yet another contributory factor for unintelligible vowel production.

Question 5: Have you ever been corrected when you use/o/for/o/or vice versa?

As shown in Table six, none of the respondents has ever received feedback on the vowel contrast when they produced/o/in lieu of/o/or vice versa despite the fact that all of them had been learning English as a Second Language for more than ten years at school which brings into the fore that ample listening opportunities are of no avail without proper feedback on pronunciation to rectify pronunciation errors.

In sum, it can be noted that the lack of awareness and the lack of guidance are the two vital factors that account for pronunciation intelligibility and that stabilize erroneous forms albeit learners have a gamut of opportunities to listen to the English language daily.

\section{DISCUSSION AND CONCLUSION}

As discussed in the literature review, the lack of awareness, the lack of exposure, motivation, the age of learning, and loan words attribute for English as a Second language learners to produce deviated sounds from the codified norms. Focusing on reasons for fossilization, the current study also confirms that the lack of awareness and lack of proper guidance are leading causes for the fossilization of erroneous forms which is echoed in Senaratne (2011). As she states the lack of 'awareness' of English phonological patterns and accepted pronunciation patterns have resulted in equivalent classification. Similarly, Wijetunga (2008) justifies that the lack of prominence given to pronunciation instruction may be a reason that has made the task of perceiving distinct sounds challenging. Flege (1992), Rochet (1995) and Flege \& MacKay (2004) discovered that learners fail to perceive the phonetic differences between L1 sounds and corresponding L2 sounds as they fail to modify previously established phonetic categories without proper instruction. Flege, Bohn \& Jang (1997) investigated that language exposure is also a factor that affects accurate production. However, the current study has proven that the exposure without proper instruction is of no avail as highlighted in Flege (1992) which explored that learners' insufficient knowledge of the L2 sounds system cause L2 learners to form phonetically deviated forms as advocated by Flege, Bohn \& Jang (1997) and Thomson (2011) which ascertain a direct link between perception and production. Similarly, Cooper (2006) has investigated that explicit instruction has a direct bearing on phonological development which upholds that the lack of guidance and the lack of awareness are the leading causes of fossilization.

Besides, the Noticing Hypothesis, the Output Hypothesis, and the Interactional model attest that opportunities should be available for learners to notice the gap between their interlanguage and the target form to crack fossilized forms and imprint the correct form in their brain. This echoes in Thomson (2011) which ascertain that phonological aspects should be perceived first in order to be produced accurately. In Flege (1992) and Rochet, (1995) it is stated that the learners assimilate vowel sounds as they fail to modify previously established sounds which is in harmony with Flege, Bohn \& Jang (1997) which confirms that L2 learners produce sounds as they perceive due to the lack of opportunities for learners to produce accurate forms subsequent to notice the gaps in their output.

Therefore, the lack of proper guidance and awareness can be considered as powerful factors that hider pronunciation intelligibility of English as Second Language learners over the factors such as the age of learning, the exposure to the language and the first language dominance. The accurate production of a new phonetic category depends totally on accurate perception which originates from awareness. In conclusion, Sri Lankan ESL learners substitute the mid back vowel/s/for the mid back vowel/o/mainly due to the lack of awareness of the existence of two distinct vowel sounds in English. As L1 phonological properties filter out L2 phonological properties, L2 learners will not notice the gaps in their interlanguage unless they are provided the opportunity to notice and produce new phonetic categories. To conclude, this study concurs that proper instruction and output opportunities in ESL classrooms are the key factors needed to rectify fossilized phonological in ESL classrooms.

\section{Future Implications}

Despite a plethora of Sri Lankan research on phonological deviations which stigmatize English as Second Language learners in Sri Lanka, the possibility of addressing fossilized phonological features through proper instruction and guidance is a marginalized area in the field of second language literature. The research-based evidence is of paramount importance which targets to find the impact of proper guidance and awareness on de-fossilizing deviated phonological features from the SSLE contrary to the firmly- based belief that fossilized phonological features are beyond addressing.

\section{REFERENCES}

Couper, G. (2006). The short and long-term effects of pronunciation instruction. Prospect, 21(1), 46-66. 
Flege, J. E. (1992). Speech learning in a second language. In C. A. Ferguson, L. Menn\& C. Stoel-Gammaon (Eds.), Phonological Development Models, Research, Publications: York Press.

Flege, J. E., Bohn, O., \& Jang, S. (1997). Effects of experience on non-native speakers' production and perception of English vowels. Journal of Phonetics, 25, 437-470. https://doi.org/10.1006/jpho.1997.0052

Flege, J. E., \& MacKay, I. R. A. (2004). Perceiving vowels in a second language. Studies in Second Language Acquisition, 26, p.13. https://doi.org/10.1017/ S027226310402611

Gunesekera, M. (2005). The Post-Colonial Identity of Sri Lankan English: Katha Publishers.

Karunarathne,I.(2003). Teaching English in urban Sri Lan$k a$ : Some pedagogical issues.10-14.

Karunatillake, W.S. (2004). An introduction to spoken Sinhala. Godage International Publishers (Pvt) Ltd.

Lippi-Green, R. (1997). English with an accent: Language, ideology, and discrimination in the United States. outledge: London and New York.

Long, M. H. (1996). The role of the linguistic environment in second language acquisition. In W. Ritchie \& T. Bhatia (Eds.), Handbook of Second Language Acquisition. San Diego: Academic Press.
Parakrama, A. (1995). De-Hegemonizing language standards: Learning from (post) colonial Englishes about 'English': St. Martin's Press.p.87. https://doi. org/10.1057/9780230371309

Rochet, B. L. (1995). Perception and production of second-language speech sounds by adults. In W. Strange (Ed.), Speech Perception and Linguistic Experience Issues in Cross-Language Research. York Press.

Senaratne, C.D. (2014). A study of Sinhalizations in Sinhala-English Mixed Discourse. Advances in Language and Literary Studies,5(6),10-17. Doi:10.7575/aiac. alls.v.5n.6p.10 https://doi.org/10.7575/aiac.alls.v.5n.6p.10

Thomson, R. I. (2011). Computer-assisted pronunciation training: Targeting second language vowel perception improves pronunciation. Calico Journal, 28(3), 744765. https://doi.org/10.11139/cj.28.3.744-765

Widyalankara, R. C. (2014). Dialectal variation in Sri Lankan English Pronunciation: An acoustic analysis. LAP Publications: Amazon.

Wijetunge, S, N. (2008)."The stigma of "Not Pot English" in Sri Lanka: A study of the production of/oland/oland implications for instructions." Master's thesis, Georgia State University, Georgia. https://scholarworks. gsu.edu/cgi/viewcontent.cgi?article $=1000 \&$ contex$\mathrm{t}=$ alesl theses 